\title{
Weather Forecast and Entropy in Information Theory
}

\author{
by \\ E. Suzuki \\ Meteorological Research Institute, Tokyo
}

(Received September 11, 1958)

\begin{abstract}
Weather forecast is generally regarded as social information containing a certain kind of uncertainty, and so information theory must be very effective for the verification of forecast technique and forecasted result.

The author tried to introduce the idea of entropy in information theory to the various problems of weather forecast, and could show that the several verification measures hitherto known were systematically identified to the ideas of relative entropy or transmitted amount of information in information theory.

Moreover, as a by-product of such induction process, a simplified method to estimate correlation coefficient could be offered, and an effective procedure to issue weather forecast under several restricting conditions was gained by the principle of maximum total entropies.

Lastly, the hypothetical examples of such procedure and actual situations were schematically shown for the daily temperature forecasting etc.
\end{abstract}

\section{Introduction}

The economic utility or the operations research of weather forecasts were recently discussed by Thоmpson and others.

Verification indices of weather forecasts (results) were already studied by many authors, but their quantitative measure of uncertainty in view of operations research is not yet established.

In this paper, the author tried to introduce the entropy ideas in information theory as the quantitative measure of uncertainty in weather forecast, and showed the effective usefulness of such entropy representations in the systematic identifications and specifications of the verification indices obtained already.

Moreover, as a more effective method for issuing weather forecast, the author proposes to adopt the entropy maximum principles in view of the cost needed for weather forecast, and denoted several examples of weather forecasts as an application of such principles schematically. 
2. Specification of entropy idea in information theory for the verification of weather forecast

The multi-variate probability distribution is generally denoted by

$$
F\left(x_{1}, x_{2}, \cdots, x_{k} ; \theta_{1}, \theta_{2}, \cdots, \theta_{h}\right),
$$

where, $x_{1}, x_{2}, \cdots, x_{k}$ are stochastic variables and $\theta_{1}, \theta_{2}, \cdots, \theta_{h}$ are population parameters of distribution respectively.

Average amount of information (i.e., entropy of information)

$$
H=-\int \log F d F \text {, }
$$

is exactly the function of $\theta_{1}, \theta_{2}, \cdots, \theta_{h}$ (i.e. $H\left(\theta_{1}, \theta_{2}, \cdots, \theta_{h}\right)$ ), but the author will write as $H=H\left(x_{1}, x_{2} \cdots, x_{k}\right)$ in conformity with the ordinary custom.

The following reccurence relations are satisfied (without proof)

$$
\begin{aligned}
& H\left(x_{1}, x_{2},\right)=H\left(x_{1}\right)+H_{x_{1}}\left(x_{2}\right) \\
& \begin{aligned}
H\left(x_{1}, x_{2}, x_{3}\right)=H\left(x_{1}, x_{2}\right) & +H_{x_{1} x_{2}}\left(x_{3}\right)=H\left(x_{1}\right)+H_{x_{1}}\left(x_{2}\right)+H_{x_{1} x_{2}}\left(x_{3}\right) \\
H\left(x_{1}, x_{2}, \cdots, x_{k}\right)= & H\left(x_{1}, x_{2}, \cdots, x_{k-1}\right)+H_{x_{1} x_{2} \cdots x_{k-1}}\left(x_{k}\right) \\
= & H\left(x_{1}, x_{2}, \cdots, x_{k-2}\right)+H_{x_{1} x_{2} \cdots x_{k-2}}\left(x_{k-1}\right) \\
& +H_{x_{1} x_{2} \cdots x_{k-1}}\left(x_{k}\right)
\end{aligned} \\
&
\end{aligned}
$$

where, $H_{x_{1}}\left(x_{2}\right), H_{x_{1} x_{2}}\left(x_{3}\right), \cdots, H_{x_{1} x_{2} \cdots x_{k-1}}\left(x_{k}\right)$ are the conditional entropy of information with fixed variate $x_{1} ; x_{1}, x_{2} ; \cdots ; x_{1}, x_{2}, \cdots, x_{k-1}$ respectively.

In the case of multi-variate normal distribution

$$
F^{\prime}\left(x_{1}, x_{2}, \cdots, x_{k} ; 0_{1}, \theta_{2}, \cdots, \theta_{h}\right)=\frac{\sqrt{|A|}}{(2 \pi)^{\frac{k}{2}}} e^{-\frac{1}{2} \sum_{i j=1}^{k} A_{i j}\left(x_{i}-\mu_{i}\right)\left(x_{j}-\mu_{j}\right),}
$$

where

$$
\begin{gathered}
|A|=\operatorname{det}\left|A_{i j}\right|, \quad A^{i j}=\sigma_{i} \sigma_{j} \rho_{i j} \quad\left|A^{i j}\right|=\left|A_{i j}\right|^{-1}(i, j=1,2, \cdots, k) \\
\mu_{i}=\text { expectation of } x_{i}, \quad \sigma_{i}{ }^{2}=\text { variance of } x_{i} \\
\rho_{i j}=\text { correlation coefficient between } x_{i} \text { and } x_{j} .
\end{gathered}
$$

Entropy function can be expressed as follows

$$
\begin{aligned}
& H\left(x_{i}\right)=\log _{c} \sqrt{2 \pi e} \sigma_{i} \quad(i=1,2, \cdots, k), \\
& H\left(x_{1}, x_{2}, \cdots, x_{k}\right)=\log _{c} \frac{(2 \pi)^{\frac{k}{2}}}{\sqrt{|A|}}+\frac{1}{2} \sum_{i j=1}^{k} A_{i j} \sigma_{i} \sigma_{j} \rho_{i j}, \\
& H_{x_{1} x_{2} \cdots x_{k-1}}\left(x_{k}\right)=\log _{e} \sqrt{2 \pi e} \sigma_{k} \sqrt{1-R^{2}{ }_{k \cdot 12 \cdots k-1}},
\end{aligned}
$$

$\left(R_{k \cdot 12 \cdots k-1}=\right.$ multiple correlation coefficient between $x_{k}$ and $\left.x_{1}, x_{2}, \cdots, x_{k-1}\right)$.

\section{(a) Verification of forecast techique}

In the statistical forecasting (linear least square prediction procedure), the above stochastic variables $x_{1}, x_{2}, \cdots, x_{k}$ are specified as 
$x_{1}, x_{2}, \cdots, x_{k-1}=$ predictors (factors by which $x_{k}$ can be estimated), $x_{k}=$ predictand (object to be predicted).

Probabilistic measure of uncertainty $H\left(x_{k}\right)$ can be considered to become the decreased uncertainty $H_{x_{1} x_{2} \cdots x_{k-1}}\left(x_{k}\right)$ by getting information concerning to $x_{1}, x_{2}, \cdots x_{k-1}$ which is connected with $x_{k}$. Consequently, conditional relative entropy (i.e. amount of information transmitted by statistical weather forecast) I is shown as follows.

$$
\begin{aligned}
I & =H\left(x_{k}\right)-H_{x_{1} x_{2} \cdots x_{k-1}}\left(x_{k}\right) \\
& =-\log _{e} \sqrt{1-R^{2}{ }_{k \cdot 12 \cdots k-1}} \quad \text { (in the case of multi-variate normal). }
\end{aligned}
$$

That is, the relative merit of weather forecast as the social information $I$ is essentially dependent on multiple correlation coefficient $R_{k \cdot 12 \cdots k-1}$ only, and such relations are probably satisfied even for the other multi-variate distribution. Generally, the natural conclusion that the technique of weather forecast with good accuracy (i.e. $R$ is large) can offer a large information, will be quantitatively affirmed by introducing the idea of conditional relative entropy.

If the significance test of information transmitted by weather forecast is necessary, the next formula can naturally be adopted by transferring the significance test referring to multiple correlation coefficient $R$ in sample.

$$
F=\frac{1-\exp (-2 I)}{\exp (-2 I)} \cdot \frac{N-k^{\prime}}{k^{\prime}-1}
$$

$$
(N=\text { sample size used in calculation of } I \text { or } R) \text {, }
$$

where

$F=$ a variable following $F$-distribution with two degrees of freedom

$$
n_{1}=k^{\prime}-1, \quad n_{2}=N-k^{\prime} \quad\left(k^{\prime}=k-1\right) .
$$

Probably I in sample will be efficiently useful in the following linear least square prediction procedure.

Est. of $x_{k}: \quad\left(x_{k}-\bar{x}_{k}\right)=-\sum_{i=1}^{k-1} \frac{\sigma_{k}}{\sigma_{i}} \frac{\Delta_{k i}}{\Delta_{k k}}\left(x_{i}-\bar{x}_{i}\right)$,

Var. of estimated $x_{k}: \sigma_{k}^{2}\left(1-R_{k \cdot 12 \cdots k-1}^{2}\right)$,

$\Delta_{k i}=$ estimated cofactor of correlation determinant $\left|\rho_{i j}\right|$ for $\rho_{k i}(i=1,2, \cdots, k-1)$

$$
\Delta_{k k}=\quad \| \quad\left|\rho_{i j}\right| \text { for } \rho_{k k}=1
$$

Example.

$$
k=7, \quad x_{7}=\text { predictand, } \quad x_{1}, x_{2}, \cdots, x_{6}=\text { predictor }
$$

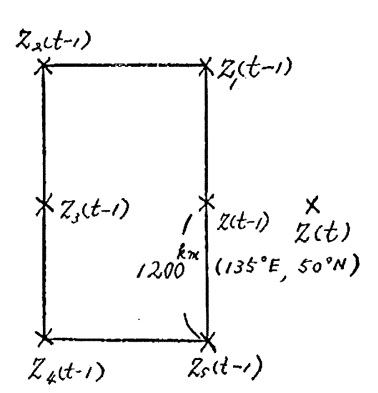

Fig. 1. Contour height $Z$ in $500 \mathrm{mb}$ surface.
Prediction of $500 \mathrm{mb}$ contour height at the gridpoint of $\left(135^{\circ} \mathrm{E}, 50^{\circ} \mathrm{N}\right)$ in January 1948. $x_{7}=Z(t)=$ contour height at $\left(135^{\circ} \mathrm{E}, 50^{\circ} \mathrm{N}\right)$ in the $t$ th day. $x_{i}=Z_{i}(t-1)=$ contour height at the gridpoint $(1200 \mathrm{~km})$ apart from $x_{7}$ in the $(t-1)$ th day $(i=1,2, \cdots 5) x_{6}=Z(t-1)=$ contour height at $\left(135^{\circ} \mathrm{E}, 50^{\circ} \mathrm{N}\right)$ in the $(t-1)$ th day.

$$
\begin{aligned}
& R_{7.12 \ldots 6} \fallingdotseq 0.703, \quad N=30, \quad k^{\prime}=6 \quad \hat{\sigma}_{7}=709.16(\mathrm{ft}) \\
& I \fallingdotseq 0.492 \quad F \fallingdotseq 4.8 \quad n_{1}=5, \quad n_{2}=24 .
\end{aligned}
$$

The value of such $I$ or $F$ is evidently significant (5\% level of significance). 


\section{(b) Verification of forecasted results}

When we assume $k=2$ in (2.5) and $x_{1}=$ actual value (or observed value), $x_{2}=$ forecasted value, conditional entropy $H_{x_{1}}\left(x_{2}\right)$ or conditional relative entropy $I\left(x_{1}, x_{2}\right)$

$$
I\left(x_{1}, x_{2}\right)=H\left(x_{2}\right)-H_{x_{1}}\left(x_{2}\right)=H\left(x_{1}\right)+H\left(x_{2}\right)-H\left(x_{1}, x_{2}\right)=I\left(x_{2}, x_{1}\right)
$$

can be adopted as the rigorous verification measure of forecasted results.

In the case of the two variate normal distribution, a formally similar relation can be easily induced as follows :

$$
I\left(x_{1}, x_{2}\right)=-\log \sqrt{1-\rho^{2}\left(x_{1}, x_{2}\right)},
$$

(where $\rho\left(x_{1}, x_{2}\right)$ is the correlation coefficient). Generally we can consider $H_{x_{1}}\left(x_{2}\right)$ and $I\left(x_{1}, x_{2}\right)$ as the verification measure of weather forecast from the viewpoint of Information theory, and such consideration can essentially correspond to $\sigma \sqrt{1-\rho^{2}}$ and $\rho$ (correlation coefficient between forecast values and observed (or readed) values.) which have been used to verify the forecasted result. So $H_{x_{1}}\left(x_{2}\right)$ and $I\left(x_{1}, x_{2}\right)$ are the more general exclusive concepts containing the verification measure, obtained already.

Moreover, in order to test the mutual independency of forecasted and observed values, we have already qualified verification measure $\chi^{2}$ for the corresponding contingency tables consisting of categorically forecasted values and corresponding observations, and even such measure $\chi^{2}$ can be reduced as a special case of $I$ as follows.

Table 1. Schematic contingency table of verification.

\begin{tabular}{c|ccccc|c}
\hline \hline forecast & $A_{1}$ & $A_{2}$ & $A_{3}$ & $\ldots \ldots$ & $A_{r}$ & Total \\
\hline$A_{1}$ & $n_{11}$ & $n_{12}$ & $n_{13}$ & $\ldots \ldots$ & $n_{1 r}$ & $n_{1}$ \\
$A_{2}$ & $n_{21}$ & $n_{22}$ & $n_{23}$ & $\ldots \ldots$ & $n_{2 r}$ & $n_{2 .}$ \\
$A_{3}$ & $n_{31}$ & $n_{32}$ & $n_{33}$ & $\ldots \ldots$ & $n_{3 r}$ & $n_{3 .}$ \\
$\vdots$ & $\vdots$ & $\vdots$ & $\vdots$ & & $\vdots$ & $\vdots$ \\
$A_{r}$ & $n_{r 1}$ & $n_{r 2}$ & $n_{r 3}$ & $\ldots \ldots$ & $n_{r r}$ & $n_{r}$. \\
\hline Total & $n_{\cdot 1}$ & $n_{\cdot 2}$ & $n_{\cdot 3}$ & $\ldots \ldots$ & $n_{\cdot r}$ & $n$. \\
\hline
\end{tabular}

As already well known, we have the following formula for the test of the contingency table (Table 1) :

$$
\chi^{2}=\sum_{i j=1}^{r} \frac{\left(n_{i j}-\frac{n_{i} \cdot n \cdot j}{n}\right)^{2}}{\left(n_{i} \cdot n_{\cdot j} / n\right)},
$$

and likelihood function $\lambda$ has the well-known asymptotic property

$$
-2 \log \lambda \rightarrow \chi^{2} \quad(n \rightarrow \infty) \text {. }
$$

On the other hand we can prove the following formula without neglecting any terms for the sample value of $I$ :

$$
I=+\log \lambda / n,
$$




$$
\begin{aligned}
& \left(\because \quad \lambda=\left[\operatorname{Max}_{p_{i j}} \pi p_{i j} p_{i j}{ }^{n_{i j}}\right] /\left[\operatorname{Max}_{p_{i} q_{j}} \pi p_{i}{ }_{i}^{n_{i} \cdot \pi} \underset{j}{\pi} q_{j}^{n^{n} \cdot j}\right]\right. \\
& =\pi_{i j}\left(n_{i j} / n\right)^{n_{i j} / \pi}(n \cdot i / n)^{n_{i} \cdot \pi} \pi_{j}(n \cdot j / n)^{n \cdot j} \\
& -\log \lambda=-\sum_{i j} n_{i j} \log \left({ }^{n_{i j}} / n\right)+\sum_{i} n_{i} \cdot \log \frac{n_{i} \cdot}{n}+\sum_{j} n_{\cdot j} \log \frac{n \cdot j}{n} \\
& \left.=\left[H\left(x_{1}, x_{2}\right)-H\left(x_{1}\right)-H\left(x_{2}\right)\right] n=-n I\left(x_{1}, x_{2}\right)\right),
\end{aligned}
$$

and so $I$ of sample contains $\chi^{2}$ as the special case that the verification measure $I$ of categorically forecasted and observed values essentially reduce $\chi^{2}$ when $n$ tends to infinity.

Other verification measures which were gained already can be reduced to conditional entropy $H_{x_{1}}\left(x_{2}\right)$ or conditional relative entropy $I\left(x_{1}, x_{2}\right)$ by slight deformations (not essential) or taking the special cases of such entropy idea.

After all, the various verification measures can be unified to the entropy idea in Information theory.

\section{A simplified procedure of the estimation of correlation coefficient as a by-product}

As a by-product of the induction process of the entropy idea in weather forecasting, a more simplified technique estimating correlation can be easily suggested.

As is already shown, conditional relative entropy (amount of transmitted information) $I$ is denoted by

$$
\begin{aligned}
I\left(x_{1}, x_{2}\right) & \doteqdot \frac{1}{n}\left(\sum_{i j} n_{i j} \log n_{i j}+n \log n-\sum_{i} n_{i} \cdot \log n_{i} \cdot-\sum_{j} n_{\cdot j} \log n_{\cdot j}\right) \\
& =-\log \sqrt{1-\rho^{2}}\left(\rho=\text { correlation coefficient between } x_{1} \text { and } x_{2}\right) .
\end{aligned}
$$

Therefore, the author readily prepared the table consisting of $n$ and $n \log _{2} n(n=$ $1 \sim 1000$ ), and the figure to estimate $\rho$ from $I$.

Table 2. Contingency Table of factor $x_{1}$ and $x_{2}$

\begin{tabular}{c|c|c}
\hline$x_{1} / x_{2}$ & $A_{i}$ & Total \\
\hline$A_{j}$ & $n_{i j}(A)$ & $n_{\cdot j}(B)$ \\
\hline Total & $n_{i \cdot}(C)$ & $n .(D)$ \\
\hline
\end{tabular}

$I=\frac{1}{\text { total number }(n)}\left[\right.$ Summation of $n_{i j} \log n_{i j}$ in the column $A+n \log n$ in the column $D$ )-(Summation of $n_{i} \cdot \log n_{i}$. in the column $C+n_{\cdot j} \log n_{. j}$ in the column $\left.B\right)$ ]. Secondly, $\rho$ can be read by Fig. 4 (sign of $\rho$ is intuitively determined in the contingency table). Actually, the estimated value of correlation coefficient is sufficiently close to the exact value of it (calculated by exact definiton formula) (difference between such two values is at most within \pm 0.03 in the case of two variate normal distributions).

Several examples of such technique given by the author as following Table. 
Table 3. Correlation coefficients of forecasted values and actual values in the several numerical predictions.

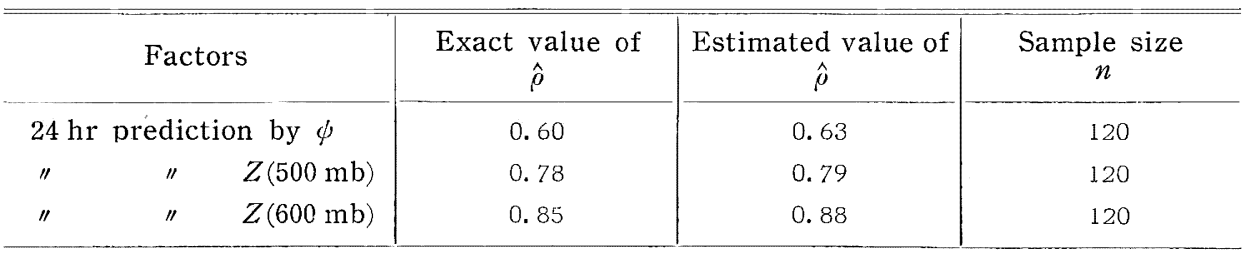

* Exact values are due to T. Murakami. $\phi=$ stream function.

For this procedure, the sampling error of estimated values is not yet fully discussed. The problems of such sampling errors and efficiency will be examined some day.

\section{Effective issue of weather forecast}

In order to formulate the operational effect of weather forecast, the author tried to use the following principles of maximum total entropy (Ideally perfect effective use of weather forecast must be discussed by the consideration of its various economic utilities).

Numerous forecasts for the various meteorological and climatological elements are actually issued at present from the Forecast Section of Japan Meteorological Agency under conditions of a limited staff and observation. Hence the following notation for the probablistic treatment of this problem can be used.

$\boldsymbol{X}_{i}=$ Meteorological or Climatological element (or phenomenon) to be forecasted on.

$p_{i 0}=$ Empirical occurrence probability of $\boldsymbol{X}_{i}$ (i.e. predictability without technical cost in forecasting),

$p_{i 1}=$ the best confidence probability attainable by the sufficient use of the cost* in the present meteorological knowledge for weather forecasting,

$c_{i}=$ cost available for the forecasting of $\boldsymbol{X}_{i}$,

$p_{i}\left(c_{i}\right)=$ confidence probability of forecasted $\boldsymbol{X}_{i}$ by the use of $\operatorname{cost} c_{i}$.

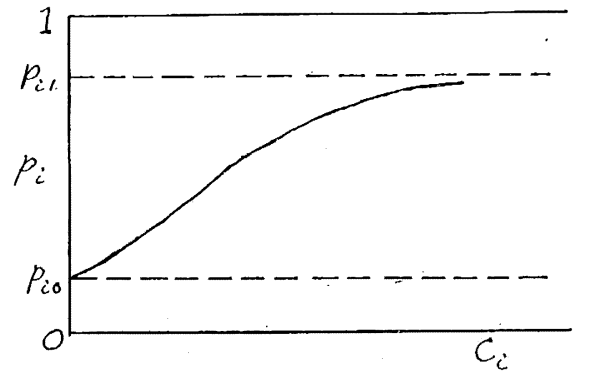

Fig. 2. Schematical illustration of the relation between $p_{i}$ and $c_{i}$.
Then, the Schematic representation of such situation can be shown as an example in Fig. 2.

When the total costs of weather forecasting $\sum_{i} c_{i}$ are limited, and the possible upper limit of cost $A$ must not be exceeded by $\sum_{i} c_{i}$ (i.e., $\sum_{i} c_{i} \leqq A$ ), we must make the following $U$ maximum for the purpose of maximizing the total amount of information $\sum_{i} \log \frac{p_{i}\left(c_{i}\right)}{p_{i 0}}$ under the restriction $\sum_{i} c_{i}=A$,

* Such cost contains, as a rule, the numerous efforts of the staff and the equipment cost to be used. 


$$
U=\sum_{i} \log \frac{p_{i}\left(c_{i}\right)}{p_{i 0}}+\lambda\left(\sum_{i} c_{i}-A\right),
$$

where, $\lambda=$ Lagrange's indeterminate multiplier. One of the curves $p_{i}\left(c_{i}\right)$ satisfying the above representation is evidently the logistic curve like the following:

$$
p_{i}\left(c_{i}\right)=p_{i 0} p_{i 1} e^{k_{i} c_{i}} /\left[p_{i 1}+p_{i 0}\left(e^{k_{i} c_{i}}-1\right)\right] \quad(i=1,2, \cdots, N),
$$

where $k_{i}=$ a constant referring to $\boldsymbol{X}_{i}$.

Actual meaning of this formulation can be explained as follows. In this formula, $k_{i}$ is regarded as a constant $k$ for the forecast of the same element.

So, intuitively, the following case may be taken to explain the above functional representation of $p_{i}$ and $c_{i}$ :

$$
\begin{array}{lll}
\text { a) } p_{i 0}=0.1 & p_{i}=0.6 & p_{i 1}=0.9 \\
\text { b) } p_{i 0}=0.3 & p_{i}=0.8 & p_{i 1}=0.9 .
\end{array}
$$

The two costs which are needed to forecast for a) and b) are almost equal, but the merit of information from a) is evidently twice as large as that of information from b), and actually it is rather difficult to issue weather forecast with reliable probability $p_{i}=0.8$ for the case of $p_{i 0}=0.3$, but it is not so difficult to attain the reliable probability $p_{i}=0.6$ for the case of $p_{i 0}=0.1$ in general.

And as the probability $p_{i}$ increases with the cost $c_{i}$, constant little improvement rapidly becomes difficult.

The above schematic formula can be theoretically solved for the case of $k_{i}=k=$ const. as follows :

$$
\left\{\begin{array}{l}
\frac{\partial U}{\partial c_{i}}=\lambda+\frac{1}{p_{i}} \frac{\partial p_{i}}{\partial c_{i}}=0 \quad(i=1,2, \cdots, N) \\
\frac{1}{p_{i} \partial p_{i}}=k\left(1-\frac{p_{i 0} e^{k c_{i}}}{p_{i 1}+p_{i 0}\left(e^{k c_{i}}-1\right)}\right) .
\end{array}\right.
$$

If we put

then the solution is

$$
F=N^{-1}\left(k A-\sum_{i} \log \frac{p_{i 1}-p_{i 0}}{p_{i 0}}\right)
$$

$$
\left\{\begin{array}{l}
p_{i}=p_{i 0} \exp \left[k\left(e^{F}+1\right)^{-1}\right] c_{i} \\
p_{i}=p_{i 0} p_{i 1} e^{k c_{i}} /\left[p_{i 1}+p_{i 0}\left(e^{k_{i} c_{i}}-1\right)\right]
\end{array}\right.
$$

Similarly expanded results for the case of $k_{i} \neq$ const. (for example, $k_{i}$ is a function of $c_{i}$ ) can be shown as a more complicated form. After all, if the actual values of parameters $k_{i}, p_{i 0} p_{i 1}(i=1,2, \cdots, N)$ and $A$ are known by the any suitable method, an operational optimum policy of weather forecast will be formally established by the use of the above results.

In spite of the fact that the ideal probability $\left(p_{i 1}\right)$ can hardly be known on account of various complicated conditions, transmitted information amount $\log \left(p_{i} / p_{i 0}\right)$ is generally apt to be large when $p_{i 0}$ is small (about $\leqq 0.2$ ), but not large when $p_{i 0}$ is not small (about $\leq 0.5 \sim 0.6$ ) even if $p_{i}$ is large (about $\approx 0.8$ ), so long as we are concerned with the information theory. 
So, if we are allowed to express the above situation in an extreme form, the daily forecast of clear weather is generally not favourable for the forecaster, but the suitable forecast with the usual accuracy for the comparatively rare events in the atmosphere (gust etc.) is rather profitable to the public and favourable for the forecaster.

\section{A hypothetical example of Section 4}

In the case that the daily mean values of temperature $x_{i}$ are forecasted with the confidence probability of $75 \%$ (that is the probability that the actual value falls within the estimated value $\left.\pm 2^{\circ} \mathrm{C}\right)$ over one month $(N=30$ days $)$, the total transmitted information amount will easily be $\sum_{i=1}^{30} \log \left(0.75 / p_{i 0}\right)$, where $p_{i 0}$ is the probability of the daily data of temperature fallings climatologically within the forecated value of the $i$ th day $\hat{T}_{i} \pm 2^{\circ} \mathrm{C}$.

Maximum of $p_{i 0}$ will evidently be presented when $\hat{T}_{i}=\bar{T}_{i}=$ (climatologically normal value of the $i$ th day), so the value of $\sum_{i=1}^{30} \log \left(0.75 / p_{i 0}\right)$ is minimum when $\hat{T}_{i}=\bar{T}_{i} \quad(i=$ $1,2, \cdots, 30$ ) (Properly speaking, $p_{i 0}$ must be estimated for each forecasted value $\hat{T}_{i}$ as the probability that $T_{i}$ falls climatologically within $\hat{T}_{i} \pm 2{ }^{\circ} \mathrm{C}$ ).

When the standard deviation of daily mean value $\sigma_{\bar{T}}$ equals to $2^{\circ} \mathrm{C}$, maximum value of $p_{i 0}$ equals to 0.68 approximately.

$\operatorname{Min} \sum_{i=1}^{30} \log \left(0.75 / p_{i 0}\right) \fallingdotseq 30 \times \log (0.75 / 0.68) \fallingdotseq 4.2$ bits.

Total transmitted amount of information by the daily forecast over one month is at least greater than 4.2 bits. Similarly, if we assume $p_{i}=0.80$,

$$
\operatorname{Min} \sum_{i=1}^{30} \log \left(0.80 / p_{i 0}\right) \fallingdotseq 6.7 \text { bits. }
$$

On the other hand, if the possible maximum confidence probability $p_{i 1}$ is assumed as 0.9 and the climatological confidence probability $p_{i 0}$ is assumed as 0.68 , the term referring to the cost $e^{k_{i} c_{i}}$ can be estimated for $p_{i}=0.68,0.75,0.80$ and 0.85 respectively. And the actual standard deviation of daily mean values of temperature has

Table 4 . Increasing rate of $p_{i}$ corresponding the increase of cost $c_{i}$

\begin{tabular}{c|c}
\hline$p_{i}$ & $\exp \left[k_{i} c_{i}\right]$ \\
\hline 0.68 & 1.00 \\
0.75 & 1.65 \\
0.80 & 2.59 \\
0.85 & 5.51 \\
0.90 & $\infty$ \\
\hline
\end{tabular}
not yet regularly calculated for all the weather stations in Japan, but Mr. Yosimochi has shown his calculated result for the data of Hirosima in summer season as in Fig. 3, and Mr. Tōjō has suggested to the author that the standard deviation of daily minimum temperature of Maebasi in Spring equals to $3^{\circ} \mathrm{C}$ approximately, and in general, standard deviation $\sigma \bar{T}$ is comparatively small in summer and winter, but is comparatively large in spring and autumn, and moreover, standard daviation of temperature is generally

small in the seacoast parts of Japan, but large in the inland parts.

After all, the greater part of standard deviation of daily mean temperature is generally considered as larger than $2^{\circ} \mathrm{C}$ throughout the year as a rule (exact situation must be compared with actual calculation of such statistics), and so the forecast of daily mean temperature with success probability $75 \%$ allowing the error 
$\pm 2^{\circ} \mathrm{C}$ will be available for the public, while, on the other hand, the increase of $p_{i}$ is quite desirable when $\sigma_{\bar{T}}$ is comparatively small. However, in order to increase actually the probability $p_{i}$, we must take into account the various complicated factors and conditions involved in the daily forecast of the daily mean value of temperature,

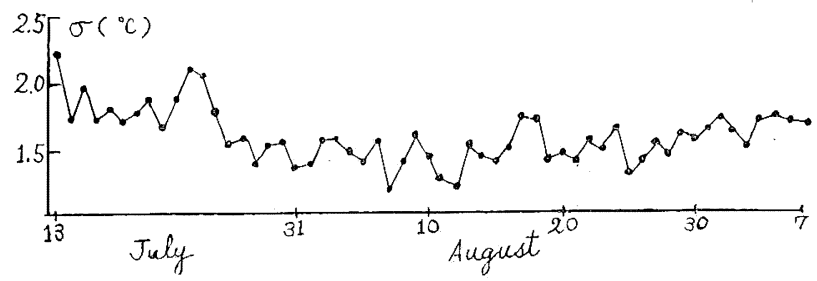

Fig. 3. An example of standard deviation of daily mean temperature of Hirosima in Summer (due to $\mathrm{Mr}$. Yosimooni).

so the coefficient $k_{i}$ in the schematic model mentioned already will actually become the very complicated function $c_{i}, p_{i}$ and $p_{i 1}$ etc, and the actual determination of such functions for $k_{i}$ will remain a future problem until suitable data of the necessary cost of forecast are sufficiently accumulated.

Suffice it, therefore, that the following hypothetical examples are considered. We have the following formula to determine the values of $c_{i}(i=1,2, \cdots, N)$ from (4.2) and (4.4):

$$
\begin{aligned}
c_{i} & =\frac{e^{F}+1}{k} \log _{e} \frac{p_{i}}{p_{i 0}}=\frac{e^{F}+1}{k} \log \left[\frac{p_{i 1} e^{k c_{i}}}{p_{i 1}+p_{i 0}\left(e^{k c_{i}}-1\right)}\right] \\
& =\left(e^{F}+1\right) k^{-1}\left[k c_{i}+\log p_{i 1}-\log \left\{p_{i 1}+p_{i 0}\left(e^{k c_{i}}-1\right)\right\}\right] .
\end{aligned}
$$

Ex 1. The case of $A=100, k=0.6, p_{i 1}=0.9, p_{i 0}=0.3, N=30$.

$F=\left(0,6 \times 100-30 \log _{e} 2\right) / 30=2-\log _{e} 2 \fallingdotseq 1.3$

$c_{i} \fallingdotseq 3.3 \quad p_{i} \fallingdotseq 0.49$

- $\sum_{i} \log _{2} \frac{p_{i}}{p_{i 0}}=\frac{k A}{e^{F}+1} \log _{2} e \doteqdot 20$ bits (Maximum amount of information).

So the forecaster issues the forecasts with probability of success $\sim 0.5$ by using cost about 3.3 over the 30 times of a certain period.

(For example, the daily forecast of rainfall at a certain rainy station over one month will probably be a case in point).

Ex 2. The case of $A=10, k=0.5, p_{10}=0.3, p_{11}=0.9, p_{20}=0.2, p_{21}=0.9$ and $N=2$.

$$
\begin{aligned}
& F=\frac{1}{2}\left(10 \times 0.5-\log \frac{0.9-0.3}{0.3}-\log \frac{0.9-0.2}{0.2}\right) \fallingdotseq 2.5-\log \sqrt{7}, \\
& c_{1} \fallingdotseq 4 \quad c_{2} \fallingdotseq 6 \quad p_{1} \fallingdotseq 0.42 \quad p_{2} \fallingdotseq 0.35 \quad\left(p_{i} \fallingdotseq p_{i 0} e^{0.072 c_{i}} \quad i=1,2\right) \\
& \text { Maximum amount of information } \doteqdot 1.3 \text { bits. }
\end{aligned}
$$

So the forecaster issues the forecast with $\ddot{p_{1}} \sim 0.42$ by using cost 4 for the predictand having $p_{10}=0.3, p_{11}=0.9$ and issues the forecasts with $p_{2} \sim 0.35$ by using cost 6 for the predictand having $p_{20}=0.2, p_{21}=0.9$ respectively. 


\section{Summary and Conclusion}

The author tried to introduce the idea of information theory to the several problems of weather forecast, and the main results can be summarized as follows:

1) The verification techniques of weather forecast gained already, can be identified by the idea of conditional entropy or relative conditional entropy, that is, the various verification measures already obtained can be expressed as the special case or the slight deformation (not essential) case of the idea of entropy.

Table 5. The values of $n$ and $n \log _{2} n$.

\begin{tabular}{|c|c|c|c|c|c|c|c|c|c|}
\hline$n$ & $n \log _{2} n$ & $n$ & $n \log _{2} n$ & $n$ & $n \log _{2} n$ & $n$ & $n \log _{2} n$ & $n$ & $n \log _{2} n$ \\
\hline 1 & 0 & 51 & 289.30005 & 101 & 672.49335 & 155 & 1127.8234 & 510 & 4587.2201 \\
\hline 2 & 2.00000 & 52 & 296.42860 & 102 & 680.60214 & 160 & 1171.5344 & 520 & 4691.7260 \\
\hline 3 & 4.75497 & 53 & 303.58718 & 103 & 688.72495 & 165 & 1215.4675 & 530 & 4796.5318 \\
\hline 4 & 8.00000 & 54 & 310.77000 & 104 & 696.85928 & 170 & 1259.6235 & 540 & 4901.5800 \\
\hline 5 & 11.60990 & 55 & 317.98140 & 104 & 705.01095 & 175 & 1303.9915 & 550 & 5006.9140 \\
\hline 6 & 15.51006 & 56 & 325.21944 & 106 & 713.17648 & 180 & 1348.5618 & 560 & 5.112 .5144 \\
\hline 7 & 19.65194 & 57 & 332.48100 & 107 & 721.35120 & 185 & 1393.3349 & 570 & 5218.3500 \\
\hline 8 & 24.00000 & 58 & 339.77038 & 108 & 729.54216 & 190 & 1438.3019 & 580 & 5324.4638 \\
\hline 9 & 28.52991 & 59 & 347.08284 & 109 & 737.74906 & 195 & 1483.4586 & 590 & 5430.8084 \\
\hline 10 & 33.22000 & 60 & 354.46080 & 110 & 745.96500 & 200 & 1528.8040 & 600 & 5537.4060 \\
\hline 11 & 38.05450 & 61 & 361.78307 & 111 & 754.19505 & 205 & 1574.3241 & 610 & 5644.2507 \\
\hline 12 & 43.02048 & 62 & 369.16784 & 112 & 762.44112 & 210 & 1620.0261 & 620 & 5751.3184 \\
\hline 13 & 48.10663 & 63 & .376 .57683 & 113 & 770.69729 & 215 & 1665.8995 & 630 & 5858.6283 \\
\hline 14 & 53.30416 & 64 & 384.00000 & 114 & 778.96428 & 220 & 1711.9344 & 640 & 5966.1632 \\
\hline 15 & 58.60455 & 65 & 391.46185 & 115 & 787.24975 & 225 & 1758.1365 & 650 & 6073.9185 \\
\hline 16 & 64.00000 & 66 & 398.93766 & 116 & 795.54424 & 230 & 1804.5041 & 660 & 6183.3420 \\
\hline 17 & 69.48835 & 67 & 406.43540 & 117 & 803.85201 & 235 & 1851.0221 & 670 & 6290.0940 \\
\hline 18 & 75.06018 & 68 & 413.95680 & 118 & 812.16922 & 240 & 1897.6944 & 680 & 6398.5280 \\
\hline 19 & 80.71219 & 69 & 421.49754 & 119 & 820.50262 & 245 & 1944.5209 & 690 & 6507.1554 \\
\hline 20 & 86.44040 & 70 & 429.05940 & 120 & 828.84480 & 250 & 1991.4900 & 700 & 6615.9940 \\
\hline 21 & 92.24061 & 71 & 436.64219 & 121 & 837.20263 & 255 & 2038.6051 & 710 & 6725.0419 \\
\hline 22 & 98.10944 & 72 & 444.24360 & 122 & 845.56585 & 260 & 2085.8578 & 720 & 6834.2760 \\
\hline 23 & 104.04441 & 73 & 451.86635 & 123 & 853.94964 & 265 & 2133.2606 & 730 & 6943.7235 \\
\hline 24 & 110.04144 & 74 & 459.50892 & 124 & 862.33816 & 270 & 2180.7846 & 740 & 7053.3692 \\
\hline 25 & 116.09900 & 75 & 467.17125 & 125 & 870.74250 & 275 & 2228.4487 & 750 & 7163.2125 \\
\hline 26 & 122.21378 & 76 & 474.85180 & 126 & 879.15618 & 280 & 2276.2516 & 760 & 7273.2380 \\
\hline 27 & 128.38446 & 77 & 482.55284 & 127 & 887.58014 & 285 & 2324.1693 & 770 & 7383.4684 \\
\hline 28 & 134.60916 & 78 & 490.27056 & 128 & 896.00000 & 290 & 2372.2261 & 780 & 7493.8656 \\
\hline 29 & 140.88461 & 79 & 498.01047 & 129 & 904.46802 & 295 & 2420.3983 & 790 & 7604.4847 \\
\hline 30 & 147.20970 & 80 & 505.76480 & 130 & 912.92630 & 300 & 2468.6970 & 800 & 7715.2480 \\
\hline 31 & 153.58330 & 81 & 513.54000 & 131 & 921.39767 & 310 & 2565.6530 & 810 & 7826.2200 \\
\hline 32 & 160.00000 & 82 & 521.32976 & 132 & 929.87796 & 320 & 2663.0752 & 820 & 7937.3376 \\
\hline 33 & 166.46817 & 83 & 529.13994 & 133 & 938.37219 & 330 & 2760.9417 & 830 & 8048.6594 \\
\hline 34 & 172.97772 & 84 & 536.96664 & 134 & 946.87482 & 340 & 2859.2572 & 840 & 8160.1464 \\
\hline 35 & 179.52900 & 85 & 544.81005 & 135 & 955.38960 & 350 & 2957.9900 & 850 & 8271.8005 \\
\hline 36 & 186.12108 & 86 & 552.67126 & 136 & 963.91632 & 360 & 3057.1308 & 860 & 8383.6326 \\
\hline 37 & 192.75372 & 87 & 560.54883 & 137 & 972.45066 & 370 & 3156.6772 & 870 & 8495.6283 \\
\hline 38 & 199.34514 & 88 & 568.44128 & 138 & 980.99784 & 380 & 3256.6114 & 880 & 8607.7728 \\
\hline 39 & 206.13541 & 89 & 576.35243 & 139 & 989.55212 & 390 & 3356.9250 & 890 & 8720.1043 \\
\hline 40 & 212.88162 & 90 & 584.27910 & 140 & 998.12160 & 400 & 3457.6160 & 900 & 8832.5910 \\
\hline 41 & 219.66406 & 91 & 592.22163 & 141 & 1006.6991 & 410 & 3558.6606 & 910 & 8945.2363 \\
\hline 42 & 226.48248 & 92 & 600.18132 & 142 & 1015.2872 & 420 & 3660.0648 & 920 & 9058.0532 \\
\hline 43 & 233.33477 & 93 & 608.15397 & 143 & 1023.8857 & 430 & 3761.8077 & 930 & 9170.9997 \\
\hline 44 & 240.21976 & 94 & 616.14556 & 144 & 1032.4901 & 440 & 3863.8776 & 940 & 9284.1356 \\
\hline 45 & 247.13820 & 95 & 624.14905 & 145 & 1041.1101 & 450 & 3966.2820 & 950 & 9397.3905 \\
\hline 46 & 254.08974 & 96 & 632.16960 & 146 & 1049.7356 & 460 & 4069.0174 & 960 & 9510.8160 \\
\hline 47 & 261.07184 & 97 & 640.20485 & 147 & 1058.3764 & 470 & 4172.0584 & 970 & 9624.3885 \\
\hline 48 & 268.08384 & 98 & 648.25726 & 148 & 1067.0208 & 480 & 4275.3984 & 980 & 9738.1326 \\
\hline 49 & 275.12716 & 99 & 656.32248 & 149 & 1075.6816 & 490 & 4379.0516 & 990 & 9852.0048 \\
\hline 50 & 282.19900 & 100 & 664.40000 & 150 & 1084.3455 & 500 & 4482.9900 & 1000 & 9966.0000 \\
\hline
\end{tabular}




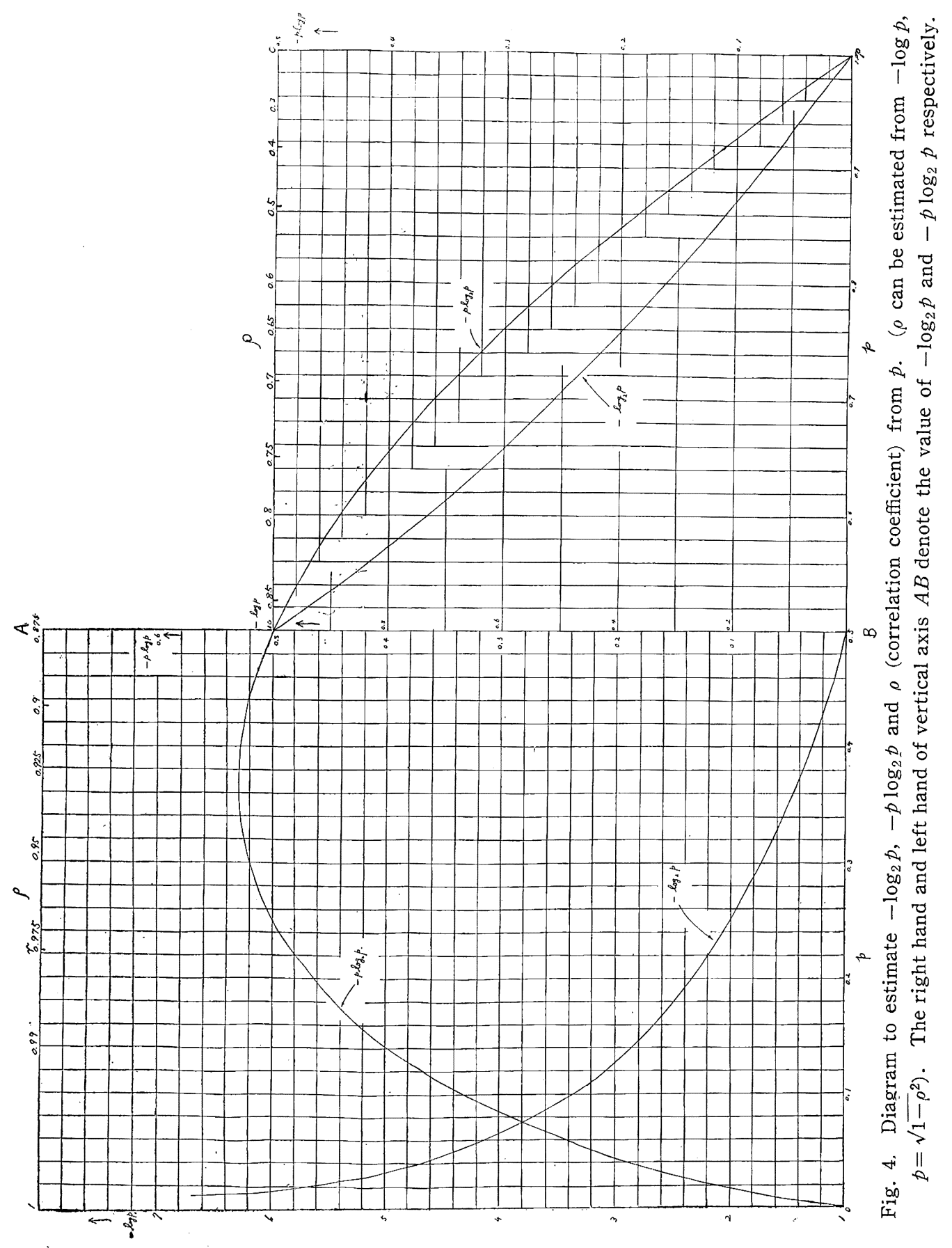


2) The idea of entropy is intuitively easier to understand than the other idea of verification, i.e. all formulations by the idea of entropies can be calculated in expressing by the number of bits ( 1 bit shows the amount of information for two equally likely events and $N$ bits generally show the amount of information for the $2^{N}$ equally likely events).

3) Numerical calculations of these entropies and the estimation of correlation are simply made by using Table 5 and Fig. 4.

4) Comparatively accurate forecasts for the rare events are generally favourable for the forecasters and necessary for the public uses, and such situation may be quantitatively explained by information theory.

5) The effective use of cost $A$ referring weather forecasts when $A$ is divided into $c_{i}\left(i=1,2, \cdots, N \sum_{i} c_{i}=A\right)$ for the issuing of the various forecasts, could be generally formulated by using the maximum entropy principle and solved by Lagrange's indeterminate multiplier, but the actual application of such solution remains a future problem.

Acknowledgements_ The author wishes to express his hearty thanks to Dr. H. Arakawa and Dr. K. Takahashi for their continual encouragements, and Dr. K. Kunisawa for his suggestions.

Thanks are also extended to Mr. A. Sunakawa and Mr. T. Honda for their generous assistance in calculation and figure drawing.

\section{References}

Thompson, J.C., 1952: On the operational deficiencies in categorical weather forecasts, Bull. Amer. Met. Soc., 33, 223-226.

Thompson, J.C., and Brier, G.W., 1955: The economic utility of weather forecasts, Month. Weath. Rev. 83, 249-254.

Tномpson, J.C., 1957: Operations research looks at the weather forecasts, Weatherwise, 10, No. $5,149-153$.

Goudnan, S., 1953: Information theory. Appendix XIII, 371-380, New York, Prentice-Hall.

BrIer, G.W., 1957: The effect of errors in estimating probabilities on the usefulness of probability forecasts. Bull. Amer. Met. Soc., 38, 76-78.

Suzurr, E., 1958: Weather forecast and OR. JUSE Operations Research, 3, No. 2, 12-30.

Yosimooni, A., 1958: Distribution of extremal high temperature in Hirosima. Applied Stat. Met. 8, 58 .

\section{天気予報と情報のエントロピー}

$$
\text { 鈴木栄一 }
$$

情報理論を天父予報に応明する研呪の第 1 歩として，次の諸点を調查した。

1. 天気予郝は不碓実さを含んだ 1 つの情報であり，情報の洒値は定量化したエントロピーその他の 確乷的测度を導入することにより，これまでの検証方式を統一的立場でまとめることができる。

2. 分割表から相関係数を簡単飞推定する方法を図表化した ( 1 つの副産物)。

3. 天気予報の効果的な出し方を情報理論の立場から定式化し，仮説的な例飞よつてその意啡を訪明

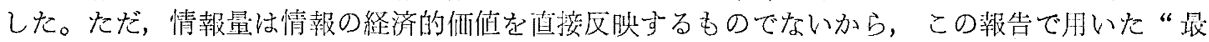
大情報の原理”は 1 つの尺度であつて，万能の尺度ではない。 